\title{
IL17-Producing $\gamma \delta$ T Cells May Enhance Humoral Immunity during Pulmonary Pseudomonas aeruginosa Infection in Mice
}

\author{
Tingting Pan ${ }^{\dagger}$, Ruoming Tan ${ }^{\dagger}$, Meiling Li, Zhaojun Liu, Xiaoli Wang, Lijun Tian, Jialin Liu * \\ and Hongping $\mathrm{Qu}$ *
}

Department of Critical Care Medicine, Ruijin Hospital, Shanghai Jiaotong University School of Medicine, Shanghai, China

\section{OPEN ACCESS}

Edited by:

Thomas A. Ficht,

Texas A\&M University, USA

Reviewed by:

Ashu Sharma,

University at Buffalo, USA

Elizabeth B. Norton,

Tulane University, USA

*Correspondence:

Jialin Liu

fillelibra@hotmail.com

Hongping Qu

hongpingqu0412@hotmail.com

${ }^{\dagger}$ These authors have contributed equally to this work.

Received: 27 July 2016 Accepted: 15 November 2016 Published: 06 December 2016

Citation:

Pan T, Tan R, Li M, Liu Z, Wang X,

Tian L, Liu J and Qu H (2016)

IL17-Producing $\gamma \delta T$ Cells May

Enhance Humoral Immunity during

Pulmonary Pseudomonas aeruginosa Infection in Mice.

Front. Cell. Infect. Microbiol. 6:170.

doi: 10.3389/fcimb.2016.00170
The host acquired immune response, especially the humoral immunity, plays key roles in preventing bacterial pneumonia in the lung. Our previous research demonstrated that interleukin 17-producing $\gamma \delta$ T cells (IL17- $\gamma \delta$ T cells) have a protective effect on the early innate immune response during acute pulmonary Pseudomonas aeruginosa infection. However, whether IL $17-\gamma \delta \mathrm{T}$ cells also play a role in humoral immunity is unknown. In this study, an acute pulmonary $P$. aeruginosa infection model was established in wild-type and $\gamma \delta \mathrm{TCR}^{-/}$C57BL/6 mice. The expression of $\mathrm{IL}-17$ on $\gamma \delta \mathrm{T}$ cells isolated from infected lung tissues increased rapidly and peaked at day 7 after acute infection with $P$. aeruginosa. Compared with wild-type infected mice, the levels of total immunoglobulins including $\operatorname{lgA}$, IgG, and IgM in the serum and BALF were significantly decreased in $\gamma \delta \mathrm{TCR}^{-/-}$mice, with the exception of IgM in the BALF. Moreover, CD69 expression in B cells from the lungs and spleen and the level of BAFF in the plasma were also decreased in $\gamma \delta \mathrm{TCR}^{-/-}$mice. IL $17-\gamma \delta \mathrm{T}$ cell transfusion significantly improved the production of immunoglobulins, B cell activation and BAFF levels in $\gamma \delta \mathrm{TCR}^{-1-}$ mice compared with $\gamma \delta \mathrm{TCR}^{-/-}$mice without transfusion; this effect was blocked when cells were pretreated with an IL-17 antibody. Together, these data demonstrate that IL $17-\gamma \delta$ T cells are involved in CD19+ $\mathrm{B}$ cell activation and the production of immunoglobulins during acute pulmonary $P$. aeruginosa infection. Thus, we conclude that IL $17-\gamma \delta T$ cells may facilitate the elimination of bacteria and improve survival through not only innate immunity but also humoral immunity.

\section{Keywords: IL17- $\gamma \delta$ T cells, B cells, B cell activating factor, immunoglobulin(s)}

\section{INTRODUCTION}

Pseudomonas aeruginosa is a Gram-negative opportunistic pathogen that causes various life-threatening infections in critical care units, especially pneumonia patients (Hong et al., 2015). $P$. aeruginosa is intrinsically resistant to several antimicrobial agents and has the capacity to acquire further resistance mechanisms (Ramakrishnan et al., 2014). The frequency of multidrug-resistant and pan-drug resistant strains of $P$. aeruginosa is high in ICUs and increases mortality, morbidity, and hospital costs (Hong et al., 2015). It has been a great challenge to develop effective drugs to treat pneumonia caused by $P$. aeruginosa, as treatment options are often limited for patients 
who are immunocompromised or have defective physical barriers (Williams et al., 2010). The most susceptible individuals to $P$. aeruginosa pneumonia include transplant recipients, neutropenic patients undergoing chemotherapy and HIV patients, often suffer from (Duraisingham et al., 2014; Savoia, 2014; Smith et al., 2014). Therefore, immunotherapy has become potent and promising adjunct to standard antimicrobial therapy against infectious diseases.

$\gamma \delta \mathrm{T}$ cells preferentially localize to epithelial and mucosal tissues and recognize antigens via an MHC unrestricted mechanism (Prinz et al., 2013). Through their induction of cytokines and chemokines, $\gamma \delta \mathrm{T}$ cells promote the differentiation and activation of monocytes, neutrophils and dendritic cells, which are involved in pathogen clearance. Depletion of $\gamma \delta \mathrm{T}$ cells leads to impaired host defense to lung infections by Klebsiella pneumonia (Moore et al., 2000), Staphylococcus aureus (Cheng et al., 2012) and Mycobacterium tuberculosis (Lockhart et al., 2006). Our previous studies found that interleukin 17-producing $\gamma \delta \mathrm{T}$ cells (IL17- $\gamma \delta \mathrm{T}$ cells) promoted neutrophil chemotaxis to enhance innate immunity and eliminate bacteria during acute P. aeruginosa infection in mice (Liu et al., 2011, 2013).

However, clearance of $P$. aeruginosa from the respiratory system requires both innate and adaptive immunity (Jensen et al., 2010). Patients with acquired immune deficiency, such as HIV patients, are more susceptible to $P$. aeruginosa infections (Movahedi et al., 2016). HIV patients with P. aeruginosa pneumonia are also more likely to become bacteraemic. In the adaptive immune response, humoral immunity is believed to protect the respiratory system from microbial infection and systematic dissemination via production of specific antibodies against the pathogen (Akcay et al., 2009). In addition to the neutralization of the pathogens, specific antibodies facilitate the removal of pathogens by phagocytes and activate the complement pathway to kill the pathogens (Ricklin et al., 2010). Approximately $20 \%$ of antibody deficient patients have had $P$. aeruginosa infections (Duraisingham et al., 2014), and it has also been reported that patients with selective IgA deficiency have a high risk of disseminated pseudomonal infections (Williams et al., 2010; Duraisingham et al., 2015).

Previous studies have shown that the levels of some immunoglobulins increase remarkably when $\gamma \delta \mathrm{T}$ cells were co-cultured with B cells (Brandes et al., 2003). It has also been reported that $\gamma \delta \mathrm{T}$ cells induce expression of essential B cell co-stimulatory molecules (Caccamo et al., 2006). An interesting study found that $\mathrm{TCR} \alpha^{-/-}$mice still efficiently develop germinal centers and produce immunoglobulins (Wen et al., 1994). These studies suggest that $\gamma \delta \mathrm{T}$ cells play import roles in humoral immunity by enhancing the activity of specific antibody-producing B cells. However, the role of $\gamma \delta \mathrm{T}$ cells, especially IL17- $\gamma \delta \mathrm{T}$ cells in humoral immunity during acute $P$. aeruginosa infection is unknown.

In this study, we built an acute $P$. aeruginosa lung infection model in $\gamma \delta$ TCR knockout $\left(\gamma \delta \mathrm{TCR}^{-/}\right)$and wild-type mice,

\footnotetext{
Abbreviations: BAFF, B cell activating factor of the TNF family; BALF, Bronchoalveolar lavage fluid; CFU, Colony-Forming Units; IL-17, Interleukin 17; IL17- $\gamma \delta$ T cells, IL17 producing- $\gamma \delta$ T cells; $P$. aeruginos $a$, Pseudomonas aeruginosa.
}

and investigated the effect of adoptive transfer of IL17- $\gamma \delta$ T cells isolated from wild-type mice. We verified the role of IL17- $\gamma \delta \mathrm{T}$ cells in humoral immunity and investigated if this role specifically required IL-17. In recent years, numerous preclinical and clinical trials of $\gamma \delta \mathrm{T}$ cell immunotherapy have been performed in various malignancies. Under these setting, $\gamma \delta \mathrm{T}$ cell immunotherapy may become a potent and promising adjunct to standard antimicrobial therapy against acute $P$. aeruginosa infection.

\section{MATERIALS AND METHODS}

\section{Materials and Animals}

Frozen aliquots of PAO1 ( $P$. aeruginosa strain 1, a derivative of the original Australian PAO isolate, provided by Y.Q. $\mathrm{Xu}$, Shanghai Jiao Tong University, China) were used for all intranasal inoculations. Pathogen-free C57BL/6 mice were purchased from the Animal Laboratory Center, Shanghai Institutes for Biological Sciences, Chinese Academy of Sciences (Shanghai, PR China) and C57BL/6 $\gamma \delta \mathrm{TCR}^{-/-}$mice (Stock Number: 002120) were purchased from the Jackson Laboratory (Farmington, CT, USA). The mice were verified to have complete loss of T cells bearing TCR $\gamma \delta$ chains in prior study (Itohara et al., 1993). All animal procedures were approved by the University Committee for Laboratory Animals in accordance with the guidelines of the Shanghai Institutes for Biological Sciences Council on Animal Care. The animals were separated into four groups: Wild type (WT) group, $\gamma \delta \mathrm{TCR}^{-/-}(\mathrm{KO})$ group, $\gamma \delta \mathrm{TCR}^{-/-}$transfused with IL17- $\gamma \delta \mathrm{T}$ cells $(\mathrm{KO}+\mathrm{T})$ group, $\gamma \delta \mathrm{TCR}^{-/-}$transfused with IL17- $\gamma \delta \mathrm{T}$ cells pretreated with an anti-IL17 antibody $(\mathrm{KO}+\mathrm{T}+\mathrm{A})$ group.

\section{Mouse Model of Pneumonia}

Mice were anesthetized by an intraperitoneal injection of a freshly prepared solution of ketamine hydrochloride and xylazine, and were intranasally infected with $P$. aeruginosa. While the mouse was held in an upright position, $10 \mu \mathrm{l}$ of a bacterial suspension of $10^{8} \mathrm{CFU} \mathrm{ml} \mathrm{m}^{-1}$ was placed in each nostril (total of $20 \mu \mathrm{l}$ per mouse). In some experiments, anti-murine IL-17 antibody ( $1 \mu \mathrm{g} / \mu \mathrm{l}$, clone 50104; R\&D Systems, Minneapolis, MN, USA) was injected intraperitoneally $24 \mathrm{~h}$ before and $72 \mathrm{~h}$ after the infection in order to neutralize IL-17 in vivo. Bronchoalveolar lavage fluid (BALF) and serum were prepared at desired time points as described below. For survival studies, $10 \mu \mathrm{l}$ of bacterial suspension at $10^{10} \mathrm{CFU} \mathrm{ml} \mathrm{m}^{-1}$ was placed in each nostril of all groups (total of $20 \mu \mathrm{l}$ per mouse) with 18-20 mice per group. The animals were kept for 4 days after infection and mortality was recorded every $8 \mathrm{~h}$.

\section{Isolation and Adoptive Transfer of IL17- $\gamma \delta$ T Cells}

Spleens were removed from healthy C57BL/6 mice, cut into small chunks, grounded gently and filtered through a $70 \mu \mathrm{m}$ nylon sieve. The resulting single cell suspension was centrifuged at 200 $\times \mathrm{g}$ for $5 \mathrm{~min}$ at $4^{\circ} \mathrm{C}$ and resuspended in RPMI 1640 medium (Invitrogen, Carlsbad, CA, USA). $\gamma \delta$ T cells were further isolated using a $\gamma \delta \mathrm{T}$ cell-specific cell isolation kit (Miltenyi Biotec, Cologne, Germany) according to the manufacturer's instructions. 
The purity of the cells was confirmed to be greater than $95 \%$ by flow cytometry.

Purified $\gamma \delta \mathrm{T}$ cells were cultured under conditions of $37^{\circ} \mathrm{C}$ and $5 \% \mathrm{CO}_{2}$ in RPMI-1640 medium supplemented with $10 \%$ fetal bovine serum (Hyclone Laboratories, Logan, UT, USA), together with a combination of recombinant mouse IL-1 $\beta$ (10 $\mathrm{ng} / \mathrm{ml}$ ) and IL23 (10 ng/ml; both from Peprotech, Rocky Hill, NJ, USA) and anti-TCR $\gamma \delta$ (GL-4.5 mg/ml; BD Pharmingen, San Diego, CA, USA). After 3 days, IL17 $-\gamma \delta$ T cells were first stained with R-phycoerythrin (PE) according to the manufacturer's instructions using the mouse IL-17 Secretion Assay-Detection Kit (Miltenyi Biotec), and then the cells were magnetically labeled with anti-PE microbeads (Miltenyi Biotec) and isolated using a magnetic activated cell sorting separator. Mice were anesthetized by an intraperitoneal injection of a freshly prepared solution of ketamine hydrochloride and xylazine. The purified IL17- $\gamma \delta$ T cells $\left(2.5 * 10^{6} / \mathrm{ml}\right.$, total of $20 \mu \mathrm{l}, 5 \times 10^{4}$ cells per mouse) were intranasally transferred to mice as required $24 \mathrm{~h}$ prior to infection.

\section{Flow Cytometry}

Single-cell suspensions were recovered from lungs as described previously (Liu et al., 2011), followed by red blood cell lysis with an $\mathrm{NH}_{4} \mathrm{Cl} /$ Tris solution. The cells were then fixed with $4 \%$ paraformaldehyde, washed twice and stained for surface markers using PE-labeled anti-CD69 (clone H1.2F3) and PEcy7-labeled anti-CD19 (clone 6D5). Isotype-matched irrelevant antibodies (all from BD Biosciences, San Diego, CA, USA) were used for control staining. The stained cells were analyzed using a FACSCalibur flow cytometer (BD Biosciences) with CellQuest software.

\section{Quantification of Serum and BALF Proteins}

To quantify serum and BALF, mice were euthanized at desired times post infection. Carefully inserted the needle (a 23-25 gauge needle and a $1 \mathrm{ml}$ syringe) into the posterior vena cava and drew blood slowly until the vessel wall collapsed. After pausing to allow the vein to refill, blood drawing was repeated three or four times or until no more blood was available. Serum was separated and stored at $-80^{\circ} \mathrm{C}$ for later use. BALF was obtained following cannulation of the trachea and three infusions of $1 \mathrm{ml}$ cold PBS containing $0.5 \mathrm{mM}$ EDTA. During the acquisition of BALF, the operation is slow and gentle to avoid damage to the surrounding blood vessels causing contamination with blood antibodies. A portion of the BALF $(100 \mu \mathrm{l})$ was plated on LB agar for bacterial colony counts. The remaining BALF was immediately centrifuged, and the supernatant was stored at $-80^{\circ} \mathrm{C}$ for later use. The levels of $\mathrm{B}$ cell activating factor of the TNF family (BAFF), IgA, IgG, and IgM in the BALF and serum were measured using specific ELISA kits (R\&D Systems, Minneapolis, MN, USA) according to the manufacturer's instructions.

\section{Quantitation of Bacterial Load in BALF}

A portion of the BALF $(100 \mu \mathrm{l})$ was plated on LB agar for bacterial colony counts after overnight incubation at $37^{\circ} \mathrm{C}$. The lower limit of detection was $1 \mathrm{CFU}$ in $100 \mu \mathrm{l}$ of the BALF, which

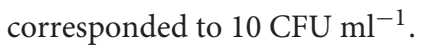

\section{Statistical Analysis}

All statistical analyses were performed using GRAPHPAD PRISM 4.00 for Windows (GraphPad Software, San Diego, CA, USA). Multi-group comparisons was all performed using an ANOVA followed by Tukey's multiple comparison test. Survival analysis was performed using the log-rank test, and the survival rate was calculated by the Kaplan-Meier method. A $p$-value $<$ 0.05 was considered statistically significant.

\section{RESULTS}

\section{The Expression of IL-17 on $\gamma \delta \mathrm{T}$ cells in the Lungs Significantly Increased after $P$. aeruginosa Pulmonary Infection in Wild-Type Mice}

We investigated the expression of IL-17 on $\gamma \delta$ T cells in the lungs of wild-type C57BL/6 mice during the immune response (day $0-14$ ) against the non-lethal $P$. aeroginosa pulmonary challenge (Liu et al., 2011). The expression of IL-17 on $\gamma \delta \mathrm{T}$ cells isolated from infected lung tissues increased rapidly and peaked at day 7 after acute infection with $P$. aeruginosa (Figure 1).

\section{IL17- $\gamma \delta$ T Cells Lead to Increased Production of IgA, IgG, and IgM in the Serum and BALF after $P$. aeruginosa Pulmonary Infection}

To investigate the roles of IL17- $\gamma \delta$ T cells in humoral immunity, the animals were separated into four groups: Wild type (WT) group, $\gamma \delta \mathrm{TCR}^{-/-}(\mathrm{KO})$ group, $\gamma \delta \mathrm{TCR}^{-/-}$transfused with IL17- $\gamma \delta$ T cells $(\mathrm{KO}+\mathrm{T})$ group, $\gamma \delta \mathrm{TCR}^{-/-}$transfused with IL17$\gamma \delta \mathrm{T}$ cells pretreated with an anti-IL17 antibody $(\mathrm{KO}+\mathrm{T}+\mathrm{A})$ group. We established the acute $P$. aeruginosa pulmonary infection model, and then measured the levels of IgA, IgG, and IgM in the serum and BALF on day 7 post infection. The concentrations of IgA, IgG and IgM in the serum and BALF were significantly higher in the WT group than the KO group, with the exception of IgM in the BALF (Figure 2). The reduced levels of $\operatorname{IgA}, \operatorname{IgG}$, and $\operatorname{IgM}$ in the $\mathrm{KO}$ group were restored by the transfusion of IL17- $\gamma \delta \mathrm{T}$ cells (Figure 2). However, when pretreated with IL-17 antibody, the effect of IL17- $\gamma \delta \mathrm{T}$ cell transfusion was blocked except with regards to serum IgG levels (Figure 2). Therefore, after infection with P. aeruginosa, IL17- $\gamma \delta$ $\mathrm{T}$ cells are required for increased production of total $\operatorname{IgA}, \mathrm{IgG}$, and $\operatorname{IgM}$ in the peripheral blood and lungs, with the exception of IgM in the BALF.

\section{IL17- $\gamma \delta$ T Cells Influence the Activation of $B$ Cells and BAFF Production during $P$. aeruginosa Pulmonary Infection}

CD69 is a marker of B cell activation (Krug et al., 2007), and we measured its expression in $\mathrm{CD} 19^{+} \mathrm{B}$ cells to explore the involvement of IL17- $\gamma \delta$ T cells in B cell activation during acute $P$. aeruginosa infection. Compared with the WT group, the levels of CD69 in $\mathrm{CD}^{+} 9^{+} \mathrm{B}$ cells in the lung and spleen on day 7 post infection were significantly decreased in the $\mathrm{KO}$ 

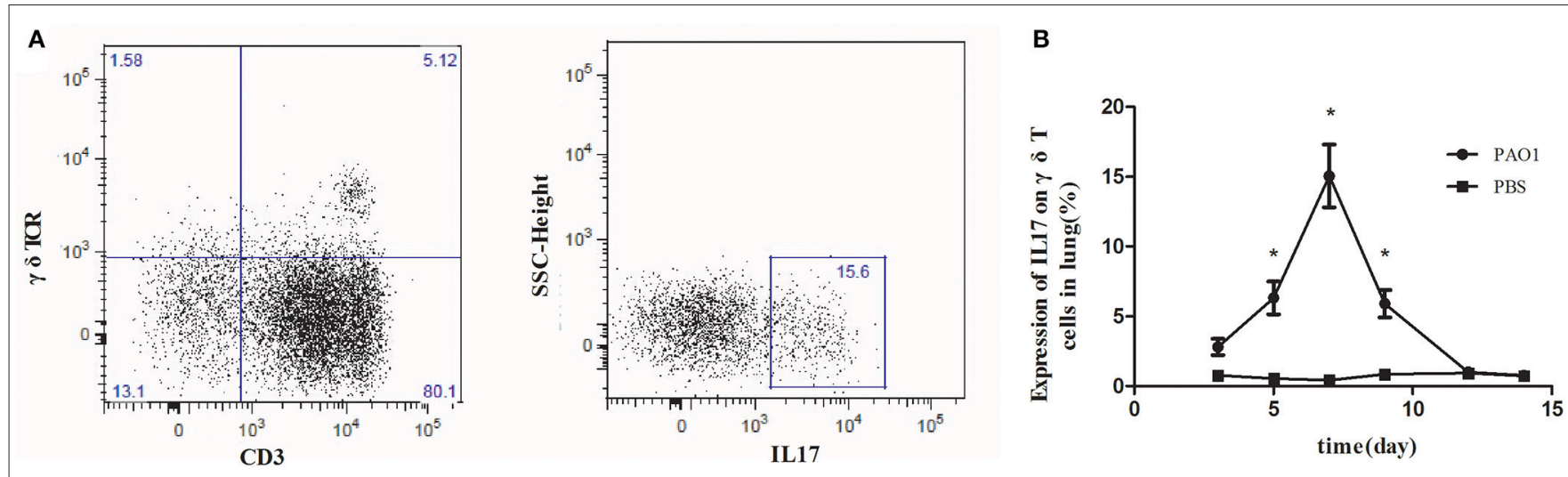

FIGURE 1 | Increased IL-17 expression on $\gamma \delta$ T cells in the lungs in response to Pseudomonas aeruginosa infection. C57BL/6 mice were inoculated with $20 \mu \mathrm{IPAO}\left(1 \times 10^{8} \mathrm{CFU} \mathrm{ml}{ }^{-1}\right)$ or PBS $(n=5)$. At 3, 5, 7, 9, 12, and 14 days following infection, lung mononuclear leukocytes were harvested from the lung, pooled and stimulated with ionomycin and phorbol 12-myristate 13-acetate for $6 \mathrm{~h}$. Lung mononuclear cells were stained with antibodies recognizing CD3, $\gamma \delta$ T-cell receptor ( $\gamma \delta$ TCR), and intracellular IL-17. The cells were first gated on CD3 and $\gamma \delta$ TCR (left, A) and then the CD3 ${ }^{+} \gamma \delta$ TCR $^{+}$cells were gated on IL-17 (right, A). The expression of IL1-7 on $\gamma \delta$ T cells was measured $(\mathbf{B})$. ${ }^{*} p$-value $<0.05$. These results represent three independent experiments.

group (WT vs. KO: Lung, $p<0.05$; spleen, $p<0.05$, Figure 3). When IL17- $\gamma \delta \mathrm{T}$ cells were transfused, B cell activation in the $\mathrm{KO}+\mathrm{T}$ group was rescued ( $\mathrm{KO}$ vs. $\mathrm{KO}+\mathrm{T}$ : Lung, $p<0.05$; spleen, $p<0.01$, Figure 3$)$. However, the effect of IL17- $\gamma \delta$ T cell transfusion was blocked if the mice were pretreated with IL-17 antibody (KO+T vs. KO+T+A: Lung, $p<0.05$; spleen, $p<0.01$, Figure 3).

BAFF, which is best known as a crucial cytokine for B cell activation and maturation (Ng et al., 2004), was measured in the serum of infected mice on day 7 post infection. Consistent with previous results, serum BAFF concentrations were lower in the KO group than the WT group (WT vs. KO, $p<$ 0.05 , Figure 4). BAFF concentrations in the $\mathrm{KO}+\mathrm{T}$ group were partially restored by the transfusion of IL17- $\gamma \delta \mathrm{T}$ cells (KO vs. $\mathrm{KO}+\mathrm{T}, p<0.05$, Figure 4 ). This effect was lost when mice were pretreated with IL-17 antibody $(\mathrm{KO}+\mathrm{T}$ vs. $\mathrm{KO}+\mathrm{T}+\mathrm{A}, p<0.05$, Figure 4). Together, these data suggest that IL17- $\gamma \delta$ T cells participate in B cell humoral immunity by influencing $\mathrm{B}$ cell activation during pulmonary $P$. aeruginosa infection.

\section{IL17- $\gamma \delta$ T Cells Contribute to the Clearance of $P$. aeruginosa after Pulmonary Infection}

To assess the role of IL17- $\gamma \delta \mathrm{T}$ cells in the clearance of $P$. aeruginosa, we measured bacterial loads in pulmonary tissue from the infected mice on day 7 post infection. Compared with the WT group, the KO group presented with significantly increased bacterial loads (WT vs. KO, $p<0.05$, Figure 5). After being transferred with IL17- $\gamma \delta \mathrm{T}$ cells, bacterial loads in the $\mathrm{KO}+\mathrm{T}$ group were restored to levels comparable to the WT group. The bacterial load in the KO group was 8fold higher than the bacterial load in $\mathrm{KO}+\mathrm{T}$ group ( $\mathrm{KO}$ vs. $\mathrm{KO}+\mathrm{T}, p<0.05$, Figure 5). However, when the animals were pretreated with IL-17 antibody, the effect of IL17- $\gamma \delta$ $\mathrm{T}$ cell transfer was lost $(\mathrm{KO}+\mathrm{T}$ vs. $\mathrm{KO}+\mathrm{T}+\mathrm{A}, p<0.05$, Figure 5).

\section{IL17- $\gamma \delta$ T Cells Improve the Survival of Mice with Pulmonary $P$. aeruginosa Infection}

We further investigated whether IL17- $\gamma \delta \mathrm{T}$ cells could improve the 96-h survival rate in a lethal $\mathrm{P}$. aeroginosa pulmonary challenge model. Compared to the WT group, the survival rate was significantly lower in the KO group (WT vs. $\mathrm{KO}, p<0.05$, Figure 6). Moreover, when IL17- $\gamma \delta \mathrm{T}$ cells were transfused, the survival rate was rescued to that of the WT group (KO vs. $\mathrm{KO}+\mathrm{T}$, $p<0.05$; WT vs. $\mathrm{KO}+\mathrm{T}, p>0.05$, Figure 6).

\section{DISCUSSION}

In this study, we addressed a crucial role of IL17- $\gamma \delta \mathrm{T}$ cells in the humoral immune response to an acute pulmonary $P$. aeruginosa infection in mice. We reported that the increased IL17 $-\gamma \delta$ T cells present in the lung following infection were involved in CD19+ B cell activation and the production of immunoglobulins including $\operatorname{IgA}, \operatorname{IgG}$, and IgM. We also found that the effect of IL17 $-\gamma \delta \mathrm{T}$ cells on humoral immunity was dependent on IL-17. Additionally, it was demonstrated that regulation of IL17- $\gamma \delta$ T cells might be a potential immunotherapy target for acute infectious diseases.

The inflammatory cytokine IL-17 plays a critical role in the immune response to infection (Iwakura et al., 2011). Although early studies believed that $\mathrm{CD} 4+\mathrm{T}$ cells are the primary source of IL-17, it has been subsequently found that $\gamma \delta$ T cells are a more potent source of IL-17 (Korn and Petermann, 2012). IL17- $\gamma \delta$ T cells function as part of the defense against bacterial infection during innate immunity (Sutton et al., 2012). In a previous study, we clarified the role of IL17- $\gamma \delta \mathrm{T}$ cells in innate immunity during acute $P$. aeruginosa pulmonary infection, measuring the proportion of IL17- $\gamma \delta \mathrm{T}$ cells in lung mononuclear leukocytes at 4,8 , and $12 \mathrm{~h}$ post infection and demonstrating that IL17- $\gamma \delta$ $\mathrm{T}$ cells participate in neutrophil chemotaxis to enhance innate immunity (Liu et al., 2011, 2013). To better understand the 

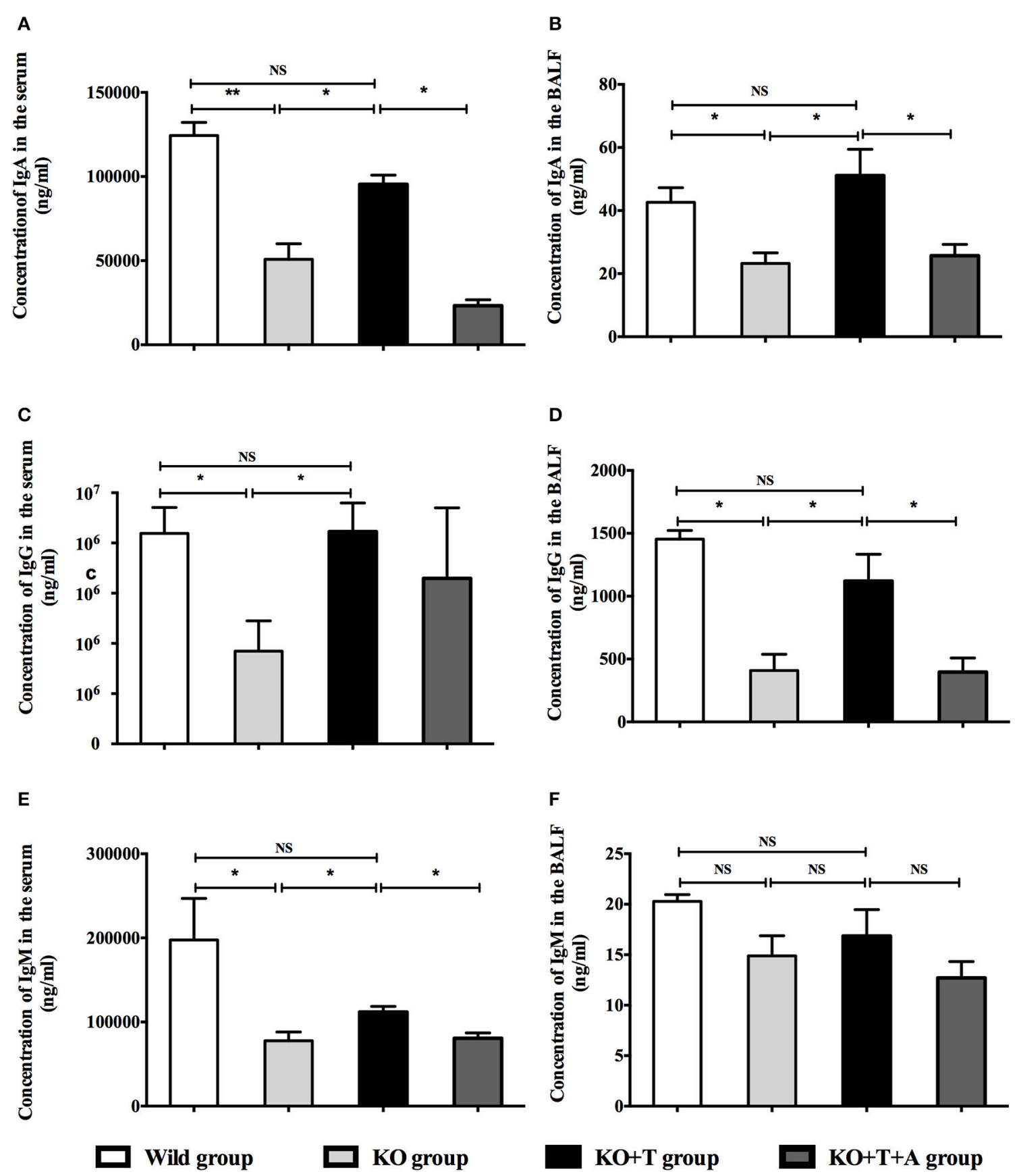

FIGURE 2 | Effect of IL17- $\gamma \delta$ T cells on IgA, IgG, and IgM production. The mice were divided into four groups: Wild type $(\mathrm{WT})$ group, $\gamma \delta$ TCR-/- (KO) group, $\gamma \delta$ $\mathrm{TCR}^{-/-}$transfused with IL17- $\gamma \delta \mathrm{T}$ cells $(\mathrm{KO}+\mathrm{T})$ group, $\gamma \delta \mathrm{TCR}{ }^{-/-}$transfused with IL $17-\gamma \delta \mathrm{T}$ cells pretreated with an anti-IL17 antibody (KO+T+A) group. All mice were inoculated with $20 \mu \mathrm{IPAO} 1\left(1 \times 10^{8} \mathrm{CFU} \mathrm{ml}{ }^{-1}\right)$. The mice in the $\mathrm{KO}+\mathrm{T}$ group and the $\mathrm{KO}+\mathrm{T}+\mathrm{A}$ group were transfused with IL 17 -producing $\gamma \delta \mathrm{T}$ cells $\left(5 \times 10^{5}\right.$ cells per mouse) $24 \mathrm{~h}$ before infection. Anti-murine IL-17 antibody (100 mg) was first administered $24 \mathrm{~h}$ before infection and again $72 \mathrm{~g}$ after infection in the $\mathrm{KO}+\mathrm{T}+\mathrm{A}$ group. On day 7 post infection, the level of $\lg A$, IgG, and IgM in the serum and BALF of all groups were measured using ELISA. (A,B) Levels of IgA in the serum and BALF. (C,D) Levels of IgG in the serum and BALF. (E,F) Levels of IgM in the serum and BALF. ${ }^{*} p<0.05$, ${ }^{* *} p<0.01$. These results represent three independent experiments.

role of IL17- $\gamma \delta \mathrm{T}$ cells in acquired immunity, we extended the detection time to $3,5,7,9,12$, and 14 days post infection. We found that the expression of IL-17 on $\gamma \delta \mathrm{T}$ cells isolated from infected lung increased rapidly, with a peak at day 7 after acute infection with $P$. aeruginosa. The results showed the possibility of IL17- $\gamma \delta \mathrm{T}$ cell involvement in humoral immunity during acute pulmonary $P$. aeruginosa infection. The role of $\gamma \delta \mathrm{T}$ cells in humoral immunity has gradually been recognized in recent 
A

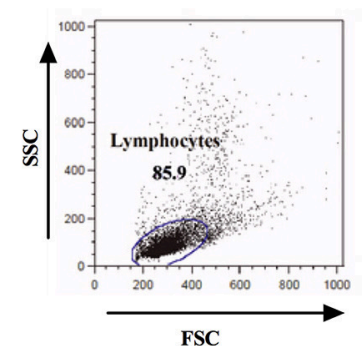

B

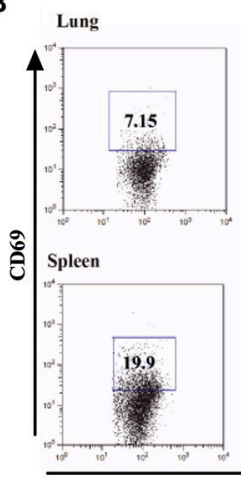

WT group

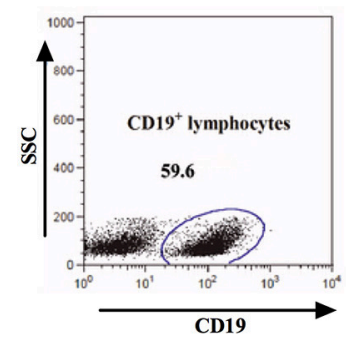

CD19

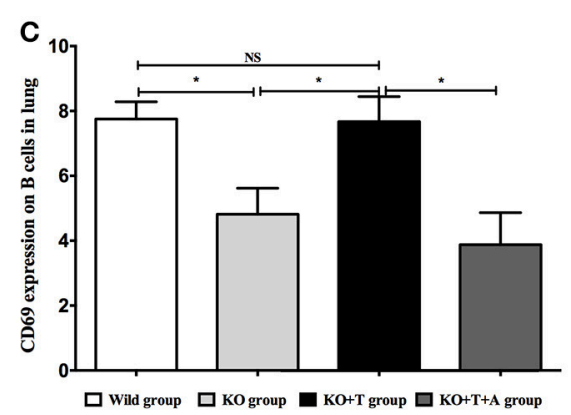

D

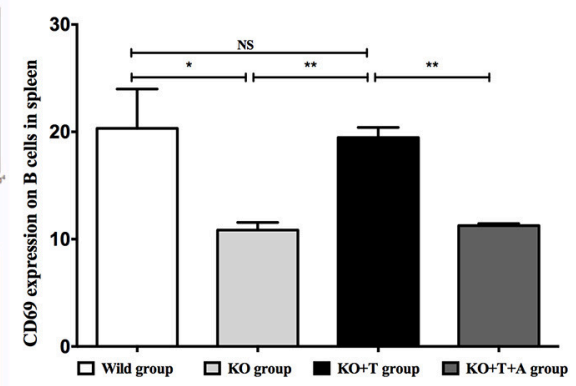

KO+T group

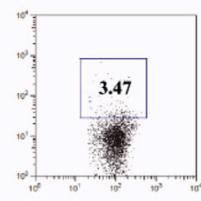

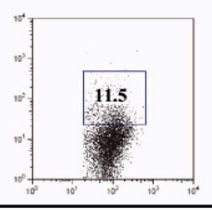

KO group
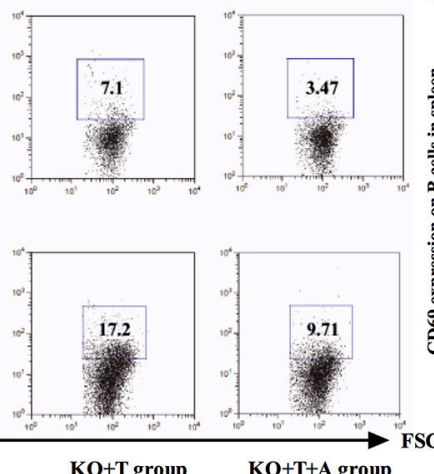

FIGURE 3 | Effect of IL17- $\gamma \delta$ T cells on B cells activation. The mice in all groups were processed as described in Figure 2. On day 7 post infection, CD69 expression in CD19+ B cells from the lung and spleen were measured. (A,B) Representative dot plots of CD69 staining in CD19+ B cells. (C) Percentage of CD19+ $B$ cells in the lung expressing CD69. (D) Percentage of CD19+ B cells in the spleen expressing CD69. ${ }^{\star} p<0.05$, ${ }^{\star *} p<0.01$. These results represent three independent experiments.

studies. Human $\mathrm{V} \delta 2^{+} \gamma \delta \mathrm{T}$ cells can help B cell maturation and antibody production in vitro, suggesting they can promote humoral immunity (Bansal et al., 2012). Additionally, IL-17, which is mainly produced by $\gamma \delta \mathrm{T}$ cells, was found to recruit B cells in mice infected with $P$. aeruginosa (Fleige et al., 2014). Thus, $\gamma \delta \mathrm{T}$ cells can have great influence not only on innate immunity but also on humoral immunity in response to infectious diseases.

Humoral immunity is the principal specific immune response to defend host against extracellular pathogenic bacteria (Stead et al., 2002). Patients with IgA deficiency may be at risk for disseminated pseudomonal infections (Duraisingham et al., 2015). In our study, IL17- $\gamma \delta \mathrm{T}$ cells promoted immunoglobulin production, including increased expression of $\operatorname{IgA}$, IgG, and IgM on day 7 post-infection. It has also been shown that the levels of some immunoglobulins increased remarkably when $\gamma \delta$ $\mathrm{T}$ cells were co-cultured with $\mathrm{B}$ cells in vitro (Caccamo et al., 2006). $\gamma \delta$ T cells can express remarkable levels of co-stimulatory molecules after stimulation, including CD40L, OX40, ICOS, and CD70, whose essential function in humoral immunity are welldocumented (Brandes et al., 2003). In this study, $\gamma \delta \mathrm{T}$ cells may facilitate $\mathrm{B}$ cell activation through direct cell-to-cell contact (Brandes et al., 2003).

In addition to this cell-to-cell contact mechanism, we found that IL17- $\gamma \delta \mathrm{T}$ cells also induce BAFF production, which may also promote $\mathrm{B}$ cell activation. BAFF is a crucial cytokine for B cell activation and survival that is secreted by $\mathrm{T}$ cells, monocytes,

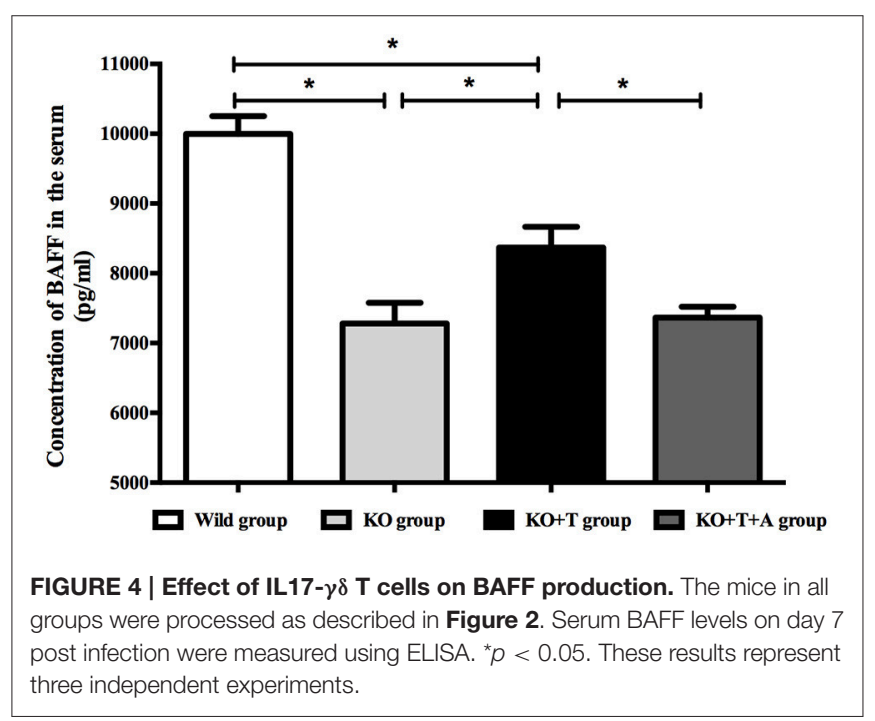

dendritic cells, and neutrophils and exists in either a membranebound or secreted form (Ng et al., 2004). In our study, we found that on day 7 post infection $B$ cell activation in the lung and spleen and serum BAFF levels were significantly decreased in $\gamma \delta \mathrm{TCR}^{-/-}$mice but could be rescued partially by IL17- $\gamma \delta \mathrm{T}$ cell transfusion. However, the effect of IL17 $-\gamma \delta$ T cell transfusion 


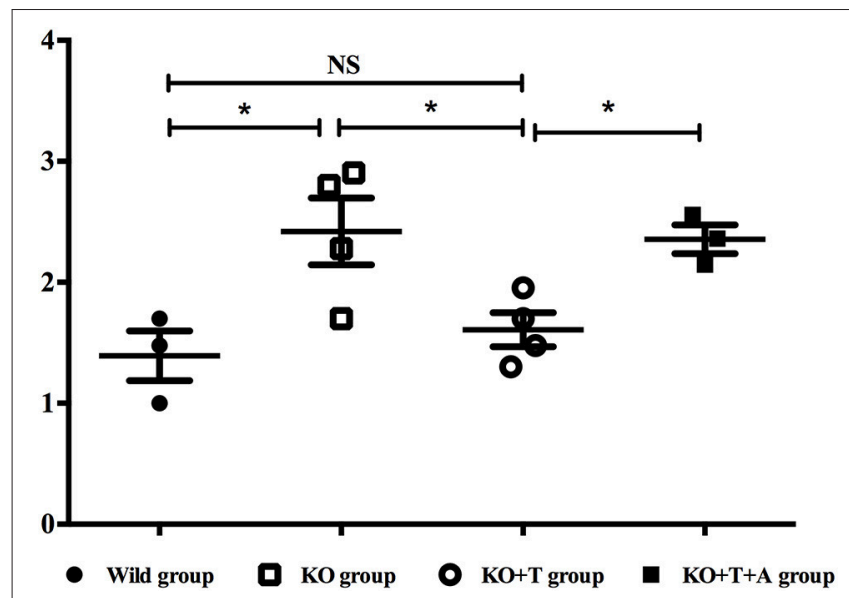

FIGURE 5 | Effect of IL17- $\gamma \delta$ T cells on bacterial clearance. BALF was obtained on day 7 post infection following cannulation of the trachea and three infusions of $1 \mathrm{ml}$ cold PBS containing $0.5 \mathrm{mM}$ EDTA. A portion of the BALF $(100 \mu \mathrm{l})$, which corresponded to $10 \mathrm{CFU} \mathrm{ml}^{-1}$, was plated on LB agar and incubated overnight at $37^{\circ} \mathrm{C}$ to determine the bacterial load. ${ }^{*} p<0.05$. These results represent three independent experiments.

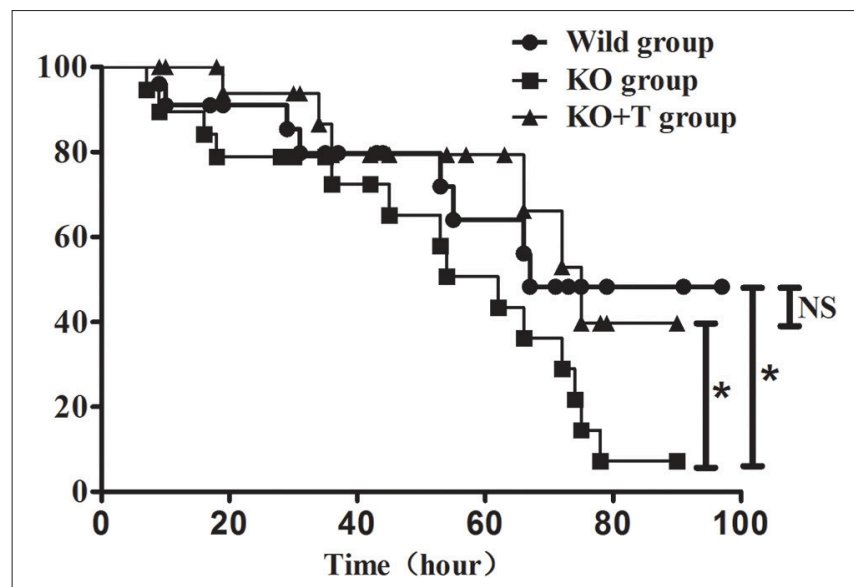

FIGURE 6 | Effect of IL17- $\gamma \delta$ T cells on the survival rate of mice with pulmonary $\boldsymbol{P}$ aeruginosa infection. Mice in the four groups were inoculated with $20 \mu \mathrm{IPAO} 1\left(1 \times 10^{10} \mathrm{CFU} \mathrm{ml}{ }^{-1}\right)$. Eighteen to twenty mice in each group were observed at least every $8 \mathrm{~h}$ until the fourth day post infection. ${ }^{*} p<0.05$. These results represent three independent experiments.

was blocked if the mice were pretreated with IL-17 antibody. Therefore, IL17 $-\gamma \delta$ T cells influenced BAFF production to induce the activation of $\mathrm{B}$ cells during humoral immunity in acute pulmonary $P$. aeruginosa infection. It has been reported that a strong positive correlation exists between serum IL-17 and BAFF levels in systemic lupus erythematous (Vincent et al., 2013). Doreau et al. reported that IL-17 acts synergistically with BAFF to influence B cell differentiation into immunoglobulin-secreting cells (Doreau et al., 2009). Therefore, IL17- $\gamma \delta \mathrm{T}$ cells may influence humoral immunity by providing cytokines, including
BAFF. In future studies, we will investigate which cells are responsible for BAFF production and how $\gamma \delta \mathrm{T}$ cells influence BAFF production.

Our studies indicated that IL17 $-\gamma \delta$ T cells can greatly influence not only innate immunity and may have a role in humoral immunity during acute $P$. aeruginosa pulmonary infection. Therefore, to elucidate the effect of IL17- $\gamma \delta$ T cells on bacterial clearance and ultimate prognosis, we measured the bacteria load in BALF from mice on day 7 post infection, finding that IL17- $\gamma \delta \mathrm{T}$ cells help to eliminate bacteria. Considering the role of inducing neutrophil chemotaxis and immunoglobulin production, IL17$\gamma \delta \mathrm{T}$ cells help eliminate bacteria through not only innate immunity but also humoral immunity. Given the effect of bacterial clearance, regulation of IL17- $\gamma \delta \mathrm{T}$ cells improved the survival rate in acute $P$. aeruginosa pulmonary infected mice. Several developmental studies and clinical trials based on active and passive immunotherapy have been performed in the last decades to prevent or treat infections due to drugresistant bacteria, particularly in immunocompromised patients, (Savoia, 2014), and numerous preclinical trials of $\gamma \delta \mathrm{T}$ cell immunotherapy have been performed in malignancies (Kang et al., 2009; Bryant et al., 2011; Zhou et al., 2012). $\gamma \delta \mathrm{T}$ cells might be a suitable immunotherapy target for acute $P$. aeruginosa pulmonary infection. Our findings provide a new understanding of the molecular mechanisms behind the immune function of $\gamma \delta \mathrm{T}$ cells, which may have implications for $\gamma \delta \mathrm{T}$ cell-based immunotherapy in $P$. aeruginosa pulmonary infection.

Although we have demonstrated that $\gamma \delta$ T cells may influence humoral immunity via IL17, as this study was exploratory and very preliminary, the mechanisms responsible for IL-17mediated $B$ cell activation and immunoglobulin production still deserve investigation in a dedicated study; future studies will also address how BAFF is involved in this process. These will be the major problems to be addressed in future work.

\section{AUTHOR CONTRIBUTIONS}

TP contributed to the conception, planning and performance of experiments, the interpretation of results and for drafting this manuscript; RT contributed to the conception, planning and performance of experiments and the interpretation of results. Both $\mathrm{ML}$ and $\mathrm{ZL}$ contributed to the conception of experiments and interpretation of results. Both XW and LT contributed to performance of experiments. JL and HQ designed the study, identified appropriate methods. All authors reviewed and approved this manuscript. TP and RT contributed equally to this work.

\section{ACKNOWLEDGMENTS}

This project was jointly supported by National Natural Science Foundation of China (Grant No. 81100004) and Natural Science Foundation of Shanghai (Grant No. 16ZR1420900). 


\section{REFERENCES}

Akcay, A., Nguyen, Q., and Edelstein, C. L. (2009). Mediators of inflammation in acute kidney injury. Mediators Inflamm. 2009, 1-12. doi: 10.1155/2009/ 137072

Bansal, R. R., Mackay, C. R., Moser, B., and Eberl, M. (2012). IL-21 enhances the potential of human gammadelta T cells to provide B-cell help. Eur. J. Immunol. 42, 110-119. doi: 10.1002/eji.201142017

Brandes, M., Willimann, K., Lang, A. B., Nam, K. H., Jin, C., Brenner, M. B., et al. (2003). Flexible migration program regulates gamma delta T-cell involvement in humoral immunity. Blood. 102, 3693-3701. doi: 10.1182/blood-2003-04-1016

Bryant, N. L., Gillespie, G. Y., Lopez, R. D., Markert, J. M., Cloud, G. A., Langford, C. P., et al. (2011). Preclinical evaluation of ex vivo expanded/activated gammadelta $\mathrm{T}$ cells for immunotherapy of glioblastoma multiforme. J. Neurooncol. 101, 179-188. doi: 10.1007/s11060-010-0245-2

Caccamo, N., Battistini, L., Bonneville, M., Poccia, F., Fournie, J. J., Meraviglia, S., et al. (2006). CXCR5 Identifies a Subset of V $\gamma$ 9V $\delta 2$ T Cells which Secrete IL-4 and IL-10 and Help B Cells for Antibody Production. J. Immunol. 177, 5290-5295. doi: 10.4049/jimmunol.177.8.5290

Cheng, P., Liu, T., Zhou, W. Y., Zhuang, Y., Peng, L. S., Zhang, J. Y., et al. (2012). Role of gamma-delta T cells in host response against Staphylococcus aureus-induced pneumonia. BMC Immunol. 13:38. doi: 10.1186/1471-217213-38

Doreau, A., Belot, A., Bastid, J., Riche, B., Trescol-Biemont, M.-C., Ranchin, B., et al. (2009). Interleukin 17 acts in synergy with B cell-activating factor to influence B cell biology and the pathophysiology of systemic lupus erythematosus. Nat. Immunol. 10, 778-785. doi: 10.1038/ni.1741

Duraisingham, S. S., Hanson, S., Buckland, M., Grigoriadou, S., and Longhurst, H. J. (2014). Pseudomonas infection in antibody deficient patients. Eur. J. Microbiol. Immunol. 4, 198-203. doi: 10.1556/EUJMI-D-14-00026

Duraisingham, S. S., Manson, A., Grigoriadou, S., Buckland, M., Tong, C. Y. W., and Longhurst, H. J. (2015). Immune deficiency: changing spectrum of pathogens. Clin. Exp. Immunol. 181, 267-274. doi: 10.1111/cei.12600

Fleige, H., Ravens, S., Moschovakis, G. L., Bolter, J., Willenzon, S., Sutter, G., et al. (2014). IL-17-induced CXCL12 recruits B cells and induces follicle formation in BALT in the absence of differentiated FDCs. J. Exp. Med. 211, 643-651. doi: 10.1084/jem.20131737

Hong, D. J., Bae, I. K., Jang, I. H., Jeong, S. H., Kang, H. K., and Lee, K. (2015). Epidemiology and characteristics of metallo-beta-lactamaseproducing Pseudomonas aeruginosa. Infect. Chemother. 47, 81-97. doi: 10.3947/ic.2015.47.2.81

Itohara, S., Mombaerts, P., Lafaille, J., Iacomini, J., Nelson, A., Clarke, A. R., et al. (1993). T cell receptor delta gene mutant mice: independent generation of alpha beta $\mathrm{T}$ cells and programmed rearrangements of gamma delta TCR genes. Cell 72, 337-348.

Iwakura, Y., Ishigame, H., Saijo, S., and Nakae, S. (2011). Functional specialization of interleukin-17 family members. Immunity 34, 149-162. doi: 10.1016/j.immuni.2011.02.012

Jensen, P. Ø., Givskov, M., Bjarnsholt, T., and Moser, C. (2010). The immune system vs. Pseudomonas aeruginosa biofilms. FEMS Immunol. Med. Microbiol. 59, 292-305. doi: 10.1111/j.1574-695X.2010.00706.x

Kang, N., Zhou, J., Zhang, T., Wang, L., Lu, F., Cui, Y., et al. (2009). Adoptive immunotherapy of lung cancer with immobilized anti-TCR $\gamma \delta$ antibodyexpanded human $\gamma \delta$ T-cells in peripheral blood. Cancer Biol. Ther. 8, 1540-1549. doi: $10.4161 /$ cbt.8.16.8950

Korn, T., and Petermann, F. (2012). Development and function of interleukin 17-producing $\gamma \delta \mathrm{T}$ cells. Ann. N. Y. Acad. Sci. 1247, 34-45. doi: $10.1111 / \mathrm{j} .1749-6632.2011 .06355 . \mathrm{x}$

Krug, L. T., Moser, J. M., Dickerson, S. M., and Speck, S. H. (2007). Inhibition of NF-kappaB activation in vivo impairs establishment of gammaherpesvirus latency. PLoS Pathog. 3:e11. doi: 10.1371/journal.ppat.0030011

Liu, J., Feng, Y., Yang, K., Li, Q., Ye, L., Han, L., et al. (2011). Early production of IL-17 protects against acute pulmonary Pseudomonas aeruginosa infection in mice. FEMS Immunol. Med. Microbiol. 61, 179-188. doi: 10.1111/j.1574-695X.2010.00764.x
Liu, J., Qu, H., Li, Q., Ye, L., Ma, G., and Wan, H. (2013). The responses of gammadelta T-cells against acute Pseudomonas aeruginosa pulmonary infection in mice via interleukin-17. Pathog. Dis. 68, 44-51. doi: 10.1111/2049-632X.12043

Lockhart, E., Green, A. M., and Flynn, J. L. (2006). IL-17 production is dominated by $\gamma \delta \mathrm{T}$ cells rather than CD4 T cells during Mycobacterium tuberculosis infection. J. Immunol. 177, 4662-4669. doi: 10.4049/jimmunol.177.7.4662

Moore, T. A., Moore, B. B., Newstead, M. W., and Standiford, T. J. (2000). $\gamma \delta$-T cells are critical for survival and early proinflammatory cytokine gene expression during murine Klebsiella pneumonia. J. Immunol. 165, 2643-2650. doi: 10.4049/jimmunol.165.5.2643

Movahedi, Z., Mahmoudi, S., Pourakbari, B., Keshavarz Valian, N., Sabouni, F., Ramezani, A., et al. (2016). Epidemiology of children with acquired immune deficiency syndrome (stage 3): a referral hospital-based study in Iran. J. Med. Virol. 88, 64-68. doi: 10.1002/jmv.24294

Ng, L. G., Sutherland, A. P. R., Newton, R., Qian, F., Cachero, T. G., Scott, M. L., et al. (2004). B cell-activating factor belonging to the TNF family (BAFF)-R is the principal BAFF receptor facilitating BAFF costimulation of circulating $\mathrm{T}$ and B cells. J. Immunol. 173, 807-817. doi: 10.4049/jimmunol.173.2.807

Prinz, I., Silva-Santos, B., and Pennington, D. J. (2013). Functional development of gammadelta T cells. Eur. J. Immunol. 43, 1988-1994. doi: 10.1002/eji.2013 43759

Ramakrishnan, K., Rajagopalan, S., Nair, S., Kenchappa, P., and Chandrakesan, S. D. (2014). Molecular characterization of metallo beta-lactamase producing multidrug resistant Pseudomonas aeruginosa from various clinical samples. Indian J. Pathol. Microbiol. 57, 579-582. doi: 10.4103/0377-4929. 142670

Ricklin, D., Hajishengallis, G., Yang, K., and Lambris, J. D. (2010). Complement: a key system for immune surveillance and homeostasis. Nat. Immunol. 11, 785-797. doi: 10.1038/ni.1923

Savoia, D. (2014). New perspectives in the management of Pseudomonas aeruginosa infections. Future Microbiol. 9, 917-928. doi: 10.2217/fmb.14.42

Smith, D. J., Hill, G. R., Bell, S. C., and Reid, D. W. (2014). Reduced mucosal associated invariant T-cells are associated with increased disease severity and Pseudomonas aeruginosa infection in cystic fibrosis. PLOS ONE 9:e109891. doi: 10.1371/journal.pone.0109891

Stead, A., Douglas, J. G., Broadfoot, C. J., Kaminski, E. R., and Herriot, R. (2002). Humoral immunity and bronchiectasis. Clin. Exp. Immunol. 130, 325-330. doi: 10.1046/j.1365-2249.2002.01974.x

Sutton, C. E., Mielke, L. A., and Mills, K. H. (2012). IL-17-producing $\gamma \delta \mathrm{T}$ cells and innate lymphoid cells. Eur. J. Immunol. 42, 2221-2231. doi: 10.1002/eji.201242569

Vincent, F. B., Northcott, M., Hoi, A., Mackay, F., and Morand, E. F. (2013). Clinical associations of serum interleukin-17 in systemic lupus erythematosus. Arthritis Res. Ther. 15, R97. doi: 10.1186/ar4277

Wen, L., Roberts, S. J., Viney, J. L., Wong, F. S., Mallick, C., Findly, R. C., et al. (1994). Immunoglobulin synthesis and generalized autoimmunity in mice congenitally deficient in alpha beta(+) T cells. Nature 369, 654-658.

Williams, B. J., Dehnbostel, J., and Blackwell, T. S. (2010). Pseudomonas aeruginosa: host defence in lung diseases. Respirology 15, 1037-1056. doi: 10.1111/j.1440-1843.2010.01819.x

Zhou, J., Kang, N., Cui, L., Ba, D., and He, W. (2012). Anti-gammadelta TCR antibody-expanded gammadelta $\mathrm{T}$ cells: a better choice for the adoptive immunotherapy of lymphoid malignancies. Cell. Mol. Immunol. 9, 34-44. doi: $10.1038 / \mathrm{cmi} .2011 .16$

Conflict of Interest Statement: The authors declare that the research was conducted in the absence of any commercial or financial relationships that could be construed as a potential conflict of interest.

Copyright (C) 2016 Pan, Tan, Li, Liu, Wang, Tian, Liu and Qu. This is an open-access article distributed under the terms of the Creative Commons Attribution License (CC $B Y)$. The use, distribution or reproduction in other forums is permitted, provided the original author(s) or licensor are credited and that the original publication in this journal is cited, in accordance with accepted academic practice. No use, distribution or reproduction is permitted which does not comply with these terms. 